\title{
EXAMINING TESTS OF SIGMA AND BETA CONVERGENCE ACROSS STATES' FIREARM BACKGROUND CHECK RATES
}

\author{
Alexi Thompson, Indiana University of Pennsylvania, U.S.A. \\ David Yerger, Indiana University of Pennsylvania, U.S.A.
}

dx.doi.org/10.18374/JIFE-21-2.4

\begin{abstract}
Utilizing techniques to measure sigma and beta convergence from the economic growth literature, this study tests for convergence across U.S. states in their rates of firearm background checks using monthly data from 1999 to 2018. The tests for unconditional beta convergence, along with limited examination of conditional beta convergence, find evidence of beta convergence across state rates of firearm background checks, indicating states with lower rates in 1999 had higher growth rates in background checks over the sample. The sigma convergence tests, however, find divergence over time with a rising trend in the dispersion of background check rates starting in November 2012. While untangling the causes of this accelerating dispersion is beyond the scope of this study, the finding of a break in trend of sigma dispersion coinciding with the 2012 Presidential election date, along with mass shootings in Aurora, Colorado and Sandy Hook, suggests rising political polarization may be playing a role.
\end{abstract}

Keywords: firearm background checks, convergence, structural break, state-level data 